\title{
Debugging and processing of H17 models inside door drawing panel process
}

\author{
Xiaodan LI \\ Qinhuangdao Institute of Technology \\ Qinhuangdao 066100,China
}

\begin{abstract}
This article from the inner door panel size, shape and structure stamping requirements detailed analyzes its main features, and on this basis, for example within the H17 car door panels, we elaborate its treatment process and commissioning, through production practice it has proved that this set of drawing within $\mathrm{H17}$ door panels meets the needs of high-volume production, the products meet the requirements, it is a good match performance.
\end{abstract}

Keywords- interior door panels; drawing die; Process; debugging

\section{INTRODUCTION}

Inner door panels are covered with pieces of the car in a class, its complex shape, molding is difficult from structural shapes, sizes and stamping requirements of view, the main features of the car cover is [1-4]:

1) A large overall size. But no matter how big the size of the cover is, and how complex shapes are, we try forming the shape of the entire space surface ridge, ribs and bosses on the surface in the first drawing. Otherwise it is easy to form impact repeatedly drawing line, line-curve, which can affect the surface quality after painting, which is not permitted by the cover.

2) A relatively small thickness. Cover is usually stamped from $0.8 \mathrm{~mm}-1.2 \mathrm{~mm}$ cold rolled steel plate. Forming processes in the automotive panel blank deformation is not a simple drawing, but drawing and bulging deformation exist composite molding. Cover drawing not only needs some drawing power, but also requires sufficient binder force in the drawing process. For blank sheet blank holder role, the purpose is not only to make the blank holder end face pressed sheet metal blank, so that under the direct effect of blank holder it is without wrinkling, more importantly, with the pressure side of the method, it creates the necessary tension, so that the rough surface abut the punch to achieve the purpose of forming.

3) Complex shape and uneven depth. Can not use simple geometric equations to describe the spatial surface; therefore we need to increase the resistance. Use reasonable arrangement drawbars to improve flow conditions in the blank holder, so each section of metal flow tends to be uniform, in order to effectively prevent wrinkling and crack.

4) Inside with local shape contour. This inner shape molding often has a great influence on the entire stamping forming, even decisive influence. Solely by external feed it is difficult to meet the requirements of the local shape of the molding, no matter how draw beads change the height and angle $\mathrm{R}$ it will appear crack phenomenon, so you need to set the molding process incision, when the blank is into the cavity to a certain extent, at first we breakthrough material, and then fed out from the incision, which prevents the crack to reach the molding requirements;

Based on the car cover parts of the above characteristics, correctly use steel deep drawing performance level, it is a reasonable choice of blank sheet size and optimal drawing direction, design and reasonable process supplementation, sheet metal mold design and drawing words are the key technical problems. The following studies are now within the H17 car door panels for drawing Process and debugging, see Figure 1.

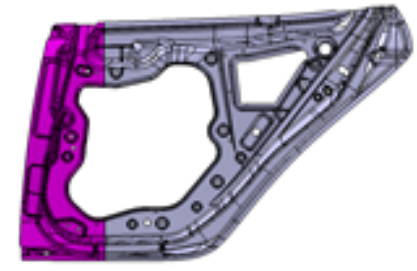

Figure $1 \mathrm{H} 17$ in the car door panels modulus

\section{DraWing Model Process}

\section{A. blank holder pad set regulator}

To make the blank feed balance settings on this drawing model blank holder 18 groups regulator pad, as shown in Figure 2. The distance between the pads are generally two regulator for $300 \mathrm{~mm}-500 \mathrm{~mm}$ one, and in the corner of the mold it must be set. Because the corner often feed more difficult, it is prone to crack or wrinkle; the regulator can be adjusted to change the height of the pad of blank holder and the molding material herein blank face pressure to make throughout the feed balanced and adequate feed. The regulator should be below the mat flat binder surface, avoiding interference occurs in the hand-pick. That pad bearing pressure regulator size is determined according to its size. $\Phi 60 \mathrm{~mm}$ regulator pad bearing pressure of generally

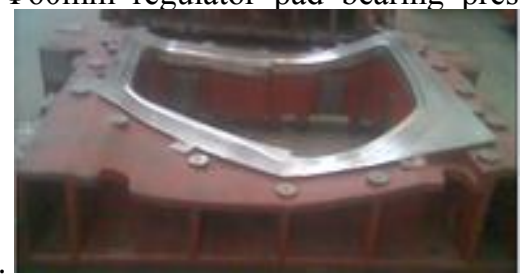

Figure 2 inner door panel H17 blank holder 


\section{B. Set on vent punch}

After the blank holder suppress rough pat, it sometimes has depression to model within a certain degree, making the punch downward when drawing blanks are between the punch and there is a certain air, in order to prevent movement in the punch to the lower point when the blank is not completely fit the mold and punch, as well as convenient back pieces, you need to punch in the final part of the molding pier open vent, to ensure there is an inner plate vent which is generally $\varphi 6-\varphi 8$ every $200 \times 200 \mathrm{~mm} 2$, this mold vent diameter is of $6 \mathrm{~mm}$, there is uniform distribution, taking account into dust, plus polyethylene snorkel is in the vent area.

\section{Process incision}

In order to achieve the drawing inside the door panels, you need to groove door panel for mounting window glass filled, the opening part of the connection into a closed shape makes addendum. But often to the formation of local antidrawing parts drawing, forming part of the general shape of this can not be supplemented by external material, which can only rely on the blank part of the bulging area to achieve the increase. So that this part of the material in the stamping process is prone to rupture, and even crack extends to the stampings, in order to solve the problems caused by the addendum, in the window of the door panel punching process incision it prevents rupture phenomenon, so that the work piece in drawing cracks to a certain extent (typically draw depth in the work piece when left $10 \mathrm{~mm}$ ), the technology edge cut sheet at the incision so that the sheet around is to supplementary material. To avoid bruising edge technology at work, the mold must rely on high precision guide post and guide sleeve guide to ensure its accuracy. Edge technology generally used in air-cooled steel is using a local quenching. General Material different blade gap of 5\% $-7 \%$ take the sheet thickness. Process-oriented mold edge portion scene photos are shown in Figure 3 and 4.
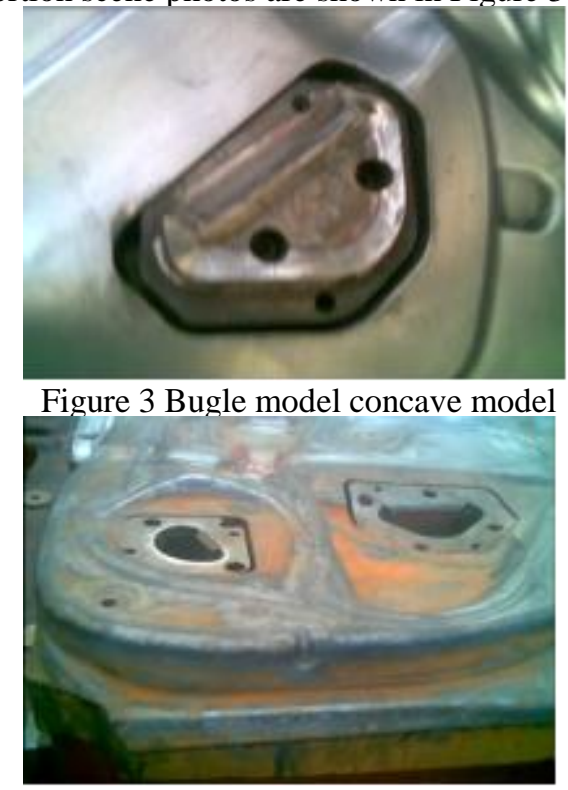

Figure 4 Bugle model concave model

\section{D. draw beads}

In the door panel of the deep drawing production, often because of the asymmetric profile of the work piece geometry, during molding the slab along the orifice around the material flow speed is not balanced, resulting in the work piece drawing after partial has thin large rupture, wrinkling and some parts have other defects. To improve this situation, it is necessary to control the feed nip surface resistance in different parts of the work piece provided that the material requires number of parts of the respective feed small resistance, but requires less material in a portion corresponding to the large feed resistance, thereby balancing the flow rate difference between the blank in the mouth portion of the model, to improve the quality of molded parts. As figure 5, the set of drawing model settings have two draw beads, the innermost layer has two circles, and the outer part sets a straight line, which increases the radial tensile stress.

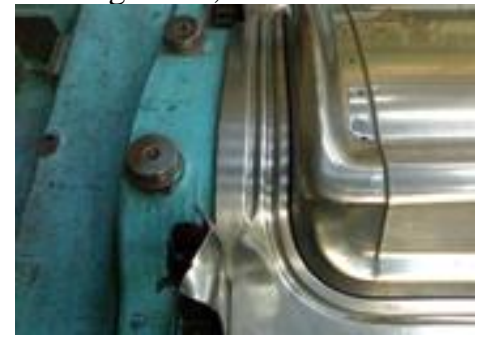

Figure 5 draw beads layout

\section{DRAWING MODEL DEBUGGING}

Developing mold coverage generally has following processes: Product digital three-dimensional model $\rightarrow$ stamping process analysis $\rightarrow$ design $\rightarrow$ produce formal mold drawings and CAM data $\rightarrow$ phantom casting $\rightarrow$ CAM machining $\rightarrow$ mold assembly $\rightarrow$ mold debugging $\rightarrow$ product testing $\rightarrow$ qualified products [5]. In the process of manufacturing a mold, it is an important step in the debugging of qualified products. Although computer technology in the mold design and processing is increasingly widely used, but it is still by fitter to repair the mold to eliminate processing errors and unreasonable design mold manufacturing process between the last to get qualified products. So drawing model debugging and research cooperation is the last link in mold making, it is the most important aspect.

\section{A. pairs of rounded handle gouging}

Usually, the inner ridge board is exactly the case with the mating surfaces of exterior parts, while a small ridge $\mathrm{R}$ angle are required, usually in $\mathrm{R} 2 \mathrm{~mm}$ around, it is unable to meet the requirements of the actual processing of mold inside door panel ridge $\mathrm{R}$ angle, due to processing of the reasons the knife, cutting allowance, etc., when less than R3mm fillet can not be processed on CNC machines, edge ridge $\mathrm{R}$ angle region is difficult to process completely, again the fitter must be trimmed. Because of sheet metal forming punch by the decision to trim most of the punch as a benchmark, it is not in place for the processing of Cheongju angle, punch $\mathrm{R}$ parts and material moving parts push light, take the material at the 
site of R 150 grit polished to eliminate knife mark, it is finishing with 200 grit polished to a surface roughness $\mathrm{Ra} 0.4$, profiles 180 \# Whetstone push light $\mathrm{R}$ angle outside until there is barely visible marks. The convex surface of the molding material grinds oil stone, $\mathrm{R}$ parts sandpaper polish and remove interference corner R3 following parts, trim process ridgeline, $\mathrm{R}$ parts can be used not deforming coarse stone grind, to avoid uneven ridge appeared, distorted, $\mathrm{R}$ angle should be smooth and round with no sharp bump, grinding together the mold is for the next step to prepare.

\section{B. Eureka of molds}

With reference to the punch model conduct research together, we make sure the fit profile, if we found imbalance problem we must find a balance point where the use of the upper and lower mold blocks is to ensure a balanced combination of research, in order to eliminate the machine face imbalance caused by the inclination of the occlusal surface mold research before they grind together; research co-guide sites, red lead powder contact surface coloration rate over $75 \%$; in the plunger from the top of the state it has always been above the molding material surface as a reference to the blank circle early research together, drawing attention to the surrounding tendons face deep research together; used with the product requirements of the same thickness, material form at only draw bead state and press out draw bead confirm eureka effects; and then lap together, study together until the rate is more than $90 \%$, binder surface are until no wrinkles. Finally ready to face the model grind together, bring up the parts, the parts will commission a red lead powder coated on both sides by clamping down repeatedly with a piece on the type of surface grind together, to ensure the quality of mold.

Generally we do not use the debugging process to adjust the pad while adjusting the pad, although the pieces are made quickly, but in nature it is very unstable parts per commissioning process generally required to re-adjust the pad to adjust the height, otherwise there will be pulling parts cracking or wrinkling. Because the pad will adjust the gap and it is greater than the thickness of a sheet metal between the punch and model, while drawing always draws beads first forming, then there is the relative movement of the lower mold to make parts molding. After forming draw beads, the upper and lower mold gap is greater than a thickness, the blank holder and the molding material surface is not tight due to the pressure caused by the sheet wrinkling, and even squeeze result feed material resistance which is too large, and cause the crack. While adjusting the pad does not use a period piece elongated upper and lower mold material thickness equal to the gap, but the parts of the problem are completely exposed for analysis to find the problem.

\section{Conclusions}

Model debugging purposes is the final assembly of qualified white body, through the above process and the required transfer mode processing, the production proved that this set of drawing model is within H17 door panels to meet the needs of high-volume production, the products meet all the requirement, stable quality, high efficiency, and good matching performance.

\section{References}

[1] Cui LinJiang. cars Stamping Technology [M] Beijing: Mechanical Industry Press, 2003.

[2] car factory tooling design studios auto cover die [M] Beijing: Mechanical Industry Press, 1979.

[3] Zhong XiangShan drawing die design basis [M] Beijing: Mechanical Industry Press, 2010.

[4] Guo Chunsheng large car cover mold [M] Beijing: National Defense Industry Press, 1993

[5] Chen Dingkui, Ma Jian debugging large automotive panel die [J] mold manufacturing, 2003, (3): $53 \sim 54$. 